\title{
Comparison of oral and intravenous Alfacalcidol in chronic hemodialysis patients
}

Myriam Lessard, Denis Ouimet, Martine Leblanc, Annie-Claire Nadeau-Fredette, Robert Bell, Jean-Philippe Lafrance, Vincent Pichette and Michel Vallée*

\begin{abstract}
Background: Activated vitamin D is the mainstay of treatment for secondary hyperparathyroidism (SHPT) in chronic hemodialysis patients. However, the optimal route of administration is still debated. The aim of our study was to compare efficacy of oral vs intravenous (IV) administration of alfacalcidol in hemodialysis. A secondary objective was to determine the cost-effectiveness advantage of oral administration.
\end{abstract}

Methods: Eighty-eight chronic hemodialysis patients receiving IV alfacalcidol three times a week were included in the study. All were switched to the same dose of alfacalcidol given orally three times a week during the hemodialysis session. A budget impact analysis was performed.

Results: Mean patient age was 64 years old and $43 \%$ were males. The mean alfacalcidol dose administered was $2.1 \mathrm{\mu g}$ three times a week. After three months, serum parathormone (PTH) levels decreased from 80 to $59 \mathrm{pmol} / \mathrm{L}$ $(p=0.001)$ and total serum calcium levels increased from 2.34 to $2.40 \mathrm{mmol} / \mathrm{L}(p=0.002)$. After six months, total serum calcium levels were still significantly higher. Alfacalcidol dosage was significantly decreased during study period; the mean reduction was $0.44 \mu \mathrm{g}$ per dose. Finally, oral administration was associated with an annual cost reduction of 197678 \$CAN and an annual nursing time reduction of 25 days.

Conclusion: Our findings support that switching IV to oral administration of alfacalcidol during hemodialysis sessions may lead to a similar control of SHPT with lower doses of activated vitamin D. This is a good strategy for optimizing compliance and may allow a dose reduction because of a greater efficacy to suppress PTH. Oral administration also has significant cost-effectiveness advantages.

Keywords: Alfacalcidol administration, End-stage renal failure, Hyperparathyroidism

\section{Background}

Secondary hyperparathyroidism is an early and common complication of chronic kidney disease (CKD). This phenomenon is caused by several factors, such as calcitriol deficiency, progressive hyperphosphatemia, relative hypocalcemia and parathormone (PTH) skeletal resistance [1]. Prevalence of native vitamin D deficiency exceeds $80 \%$ in advanced CKD population [2]. We know that vitamin D plays a central role in phosphocalcic and bone metabolism in the general and the CKD population. However, 25-vitamine D needs to undergo 1- $\alpha$ hydroxylation before being active. Because kidneys are the primary site for this hydroxylation, active 1,25-

\footnotetext{
* Correspondence: mvallee.hmr@ssss.gouv.qc.ca

Hôpital Maisonneuve-Rosemont, 5415 Boulevard de l'Assomption, Montréal H1T 2 M4, Québec, Canada
}

\section{() Biomed Central}

vitamin $\mathrm{D}$ or calcitriol is consequently deficient in CKD and also contribute to PTH elevation [2]. Down regulation of vitamin D receptor (VDR) and decreased calcium sensing receptor (CaSR) on parathyroid cells have also been implicated in secondary HPT pathogenesis $[3,4]$. Such changes alter bone remodelling, may exacerbate osteoporosis and even lead to osteitis fibrosa, a pattern of renal osteodystrophy. Chronic excessive PTH levels are frequent in end-stage renal disease (ESRD) and are associated with parathyroid hyperplasia and eventually autonomous secretion. The first intervention to tackle this problem is to keep serum phosphorus level close to the normal range with diet, good dialysis and phosphate binders (PB). Once serum phosphorus is controlled, administration of activated vitamin $\mathrm{D}$ is the mainstay of treatment of SHPT in chronic hemodialysis 
(HD) patients. There are several mechanisms by which vitamin D analogs regulate PTH. Vitamin D analogs increase serum calcium levels by enhancing intestinal calcium absorption resulting in a decrease in PTH levels [5]. These analogs also produce a direct inhibition of PTH gene transcription in parathyroid cells [5]. Finally, activated vitamin $\mathrm{D}$ could also move the set point for calcium in parathyroid glands to the left side, which means that PTH secretion is reduced in response to serum calcium levels. Activated vitamin D can be administered orally, daily or intermittently and intravenously (IV three times a week during HD sessions).

Studies comparing oral and IV routes of administration for active vitamin D have found conflicting results [6-13]. The optimal route of administration for activated vitamin $\mathrm{D}$ is still debated [13] because there are limited randomized placebo-controlled studies that directly compare pulse-oral to pulse-IV activated vitamin D administration for the treatment of SHPT in ESRD.

In our HD center, IV administration is mostly used for compliance concerns in patients with uncontrolled SHPT with daily oral regimen. Moreover, alfacalcidol is preferred to calcitriol because of a lower cost. Calcitriol is thus reserved for patients with hepatic dysfunction, hypoparathyroidism following parathyroidectomy or refractory SHPT. Most previous clinical studies comparing routes of administration of activated vitamin $\mathrm{D}$ in $\mathrm{HD}$ population were conducted with calcitriol and only a few studies considered alfacalcidol administration $[11,14,15]$.

The primary objective of our study was to compare efficacy and side effects of oral versus IV in-center administration of alfacalcidol in HD. A secondary objective was to evaluate the cost-effectiveness of oral compared to IV regimen. Our hypothesis was that intermittent oral administration of alfacalcidol during HD sessions could be at least as effective as IV administration for SHPT control in regards to KDIGO guidelines [16]. Moreover, IV switch to oral administration could also represent a cost-effective strategy.

\section{Methods}

\section{Cohort definition}

We performed a retrospective observational study among subjects on chronic HD treatment for at least six months at Maisonneuve-Rosemont Hospital. All subjects treated with the same dose of alfacalcidol given IV three times a week for the last three months were included. We excluded patients with intestinal malabsorption or hepatic disease.

\section{Assessment of outcome}

Oral alfacalcidol was started at the same dose as prior IV dose and administered by nursing staff at the end of each HD treatment. Alfacalcidol dose was then adjusted according to KDIGO recommendations [16].
Collected demographic data for each patient included: age, sex, ESRD etiology, HD vintage and history of parathyroidectomy. Monthly biochemical parameters were collected for three months before and up to six months after the switch from IV to oral thrice-weekly alfacalcidol. Biochemical and pharmacological data included: serum calcium, phosphorus, albumin, bicarbonates, magnesium, intact PTH, $25(\mathrm{OH}) \mathrm{D}_{3}, 1.25(\mathrm{OH})_{2} \mathrm{D}_{3}$, alkaline phosphatase, phosphocalcic product, calcium concentration dialysis bath, dose of phosphate binders (calcium carbonate, sevelamer hydrochloride, lanthanum carbonate, aluminium/ magnesium based binders), dose of cinacalcet as well as alfacalcidol.

\section{Pharmaco-economic analysis}

Annual costs and nursing time were calculated for both oral and IV routes of administration. Ten patients were identified for the evaluation of the time and motion study required for drug administration. Annual costs included drug price, medical supplies and nursing time and were extrapolated for the six-month study and nursing time evaluation. Cost for nursing time were calculated by multiplying nursing time by average hourly wage for nephrology nurses in Quebec, including social benefits, obtained from the Quebec Ministry of Health [17].

\section{Statistical analysis}

Parameters at baseline, 3 and 6 months after the switch were compared using a Student's paired t-test.

\section{Ethical considerations}

The Research and Ethics Committee of MaisonneuveRosemont Hospital approved the study.

\section{Results}

\section{Patient characteristics}

The cohort consisted of 88 patients with a mean age of $64 \pm 14$ years; $43 \%$ were males. They represented $24 \%$ of the entire HD cohort. The mean IV alfacalcidol dose was $2,10 \pm 0.86 \mu \mathrm{g}$ three times a week at study entry and before the switch to oral alfacalcidol. Baseline characteristics, including ESRD etiologies and initial serum biochemistry results are summarized in Table 1 . No patients died or were lost to follow-up during the study.

\section{Effects on serum biochemistry and drug dosage adjustments}

Three months after switching from IV to oral alfacalcidol, total serum calcium levels increased from 2.34 to $2.40 \mathrm{mmol} / \mathrm{L}(\mathrm{p}=0.002)$, whereas serum PTH levels significantly decreased from 80 to $59 \mathrm{pmol} / \mathrm{L}$ ( $\mathrm{p}<0.001)$ and serum phosphorus levels did not change significantly (Table 2). There was a small decrease of alfacalcidol dosage from baseline to three months $(p=0.04)$. 
Table 1 Characteristics of patients at baseline ( $\mathrm{N}=88$ patients)

\begin{tabular}{lc}
\hline Characteristics & Mean or percentage \\
\hline Age (year), mean (SD) & $64(14)$ \\
Sex (male), $\mathrm{n}(\%)$ & $38(43.2)$ \\
IV dosage of alfacalcidol, mean (SD) & $2.1 \mu \mathrm{g}$ times a week (0.86) \\
ESRD etiology, $\mathrm{n}(\%)$ & \\
$\quad$ Diabetic nephropathy & $30(34)$ \\
$\quad$ Hypertensive nephropathy & $30(34)$ \\
Glomerular disease & $15(17)$ \\
Others & $13(15)$ \\
Cinacalcet use, $\mathrm{n}(\%)$ & $30(34)$ \\
Phosphate binders use, $\mathrm{n}(\%)$ & \\
Calcium based & $64(72)$ \\
Sevelamer & $50(57)$ \\
Lanthanum & $9(10)$ \\
No phosphate binder & $8(9)$ \\
25 vitamin D use, $\mathrm{n}(\%)$ & $0(0)$
\end{tabular}

Data are presented as number (percentage) or mean (standard deviation), SD: standard deviation.

However six months after the switch, the decrease of alfacalcidol dosage became statistically significant compared to baseline $(\mathrm{p}<0.001)$. There had been a $21 \%$ reduction of dosage, which corresponded to a mean reduction of $0.54 \mu \mathrm{g}$ per dose three times a week. At six months, the increase in total serum calcium was still significant $(\mathrm{p}<0.001)$ but no episodes of hypercalcemia were reported. However, serum PTH and phosphorus levels were not significantly different from baseline values. Concomitantly, serum $25(\mathrm{OH}) \mathrm{D}_{3}$ levels was clinically unchanged, although statistically reduced $(\mathrm{p}<0.001)$ while $1.25(\mathrm{OH})_{2} \mathrm{D}_{3}$ levels significantly increased from 32 at baseline to $40 \mathrm{pmol} / \mathrm{L}$ at six months $(\mathrm{p}=0.007)$. Moreover, total alkaline phosphatase level significantly decreased three months after the switch; this reduction was still significant at six months when compared to baseline levels.

There was no significant change in the cinacalcet dosage of the 30 patients under this medication during the study period. There was no significant change in phosphate binders dose; although six patients had a slight increase, eight patients had a small decrease in their phosphate binder dose and eight patients did not take phosphate binder during the study period. There was no change in dialysate calcium concentration during the study period that remains at $1.25 \mathrm{mmol} / \mathrm{L}$ for all patients.

\section{Pharmaco-economic analysis}

As shown in Table 3, annual costs related to nursing time and medical supplies were much lower with oral alfacalcidol regimen. The annual cost reduction was 7270\$CAN for the entire cohort or $82.61 \$ C A N$ per patient. More importantly, there was a ten-fold decrease in annual drug cost per patient, from $2493 \$ C A N$ for IV alfacalcidol to 329 \$CAN for oral alfacalcidol. Thus, in our unit, compared to IV, oral administration was associated with a total annual cost reduction of 197 678\$CAN (2246\$CAD per patient) and an annual nursing time reduction of 25 days.

\section{Discussion}

The primary objective of our study was to demonstrate that oral intermittent administration of alfacalcidol in HD was at least as effective as IV administration in controlling PTH. Our results demonstrated that thrice-weekly oral alfacalcidol administration is more effective than an equivalent thrice-weekly IV regimen. We also found that oral administration of alfacalcidol was associated with a significant increase of serum calcium levels, a lower serum PTH and total alkaline phosphatase levels. Reduction of serum PTH and total alkaline phosphatase are usually predictive of better bone remodelling control in SHPT [18]. Such an apparent increased efficacy was associated with a

Table 2 Biochemical parameters and alfacalcidol dose at baseline, at three months and at six months after the switch to oral administration

\begin{tabular}{|c|c|c|c|}
\hline Serum parameters & $\begin{array}{l}\text { Baseline IV alfacalcidol } \\
\text { administration }\end{array}$ & $\begin{array}{l}3 \text { months after switch } \\
\text { to oral alfacalcidol }\end{array}$ & $\begin{array}{l}6 \text { months after switch } \\
\text { to oral alfacalcidol }\end{array}$ \\
\hline Calcium, mmol/L (SD) & $2.34(0.17)$ & $2.40(0.18)^{* *}$ & $2.43(0.17)^{* *}$ \\
\hline Phosphorus, mmol/L (SD) & $1.49(0.44)$ & $1.58(0.44)$ & $1.57(0.50)$ \\
\hline $\mathrm{Ca} \times \mathrm{PO}_{4}(\mathrm{SD})$ & $3.49(1.06)$ & $3.78(1.07)^{*}$ & $3.77(1.18)$ \\
\hline Intact PTH, pmol/L (SD) & $79.7(59)$ & $58.5(56)^{* *}$ & $78.2(77)$ \\
\hline Alkaline phosphatise (SD) & $142.3(103)$ & $127.7(96)^{*}$ & $130.2(103)^{*}$ \\
\hline $25(\mathrm{OH}) \mathrm{D}_{3}, \mathrm{nmol} / \mathrm{L}(\mathrm{SD})$ & $55(20)$ & $57(24)$ & $50(21)^{* *}$ \\
\hline $1,25(\mathrm{OH}){ }_{2} \mathrm{D}_{3}(\mathrm{pmol} / \mathrm{L})(\mathrm{SD})$ & $32(19)$ & $38(17)^{*}$ & $40(18)^{*}$ \\
\hline Mean alfacalcidol dose (SD) & 2.1 Hg 3 times a week (0.86) & $1.87 \mu \mathrm{g} 3$ times a week $(0.92)^{*}$ & $1.56 \mu \mathrm{g} 3$ times a week $(0.79)^{* *}$ \\
\hline
\end{tabular}


Table 3 Estimated annual costs per patient according to alfacalcidol administration regimen

\begin{tabular}{lcc}
\hline & \multicolumn{2}{c}{ Cost per patient CAD\$ } \\
\cline { 2 - 3 } & IV administration & Oral administration \\
\hline Medical supplies & 31.20 & 0 \\
Nursing time & 64.20 & 12.80 \\
Drug & 2492.80 & 329.20 \\
Total & 2588.20 & 342.00 \\
\hline
\end{tabular}

significant decrease in alfacalcidol oral dose during the study period compared to prior IV dose. To our knowledge, this is the first study to show such findings. No episode of hypercalcemia was reported during the study period, although this remains a long-term possibility if alfacalcidol dosage is not carefully adjusted.

Several studies have shown that alfacalcidol is effective for SHPT control when compared to others forms of activated vitamin D [19-22]. Mitwalli et al. [14] reported in 2000 that oral intermittent administration of alfacalcidol was at least as effective as IV administration in controlling serum PTH. Although all patients were initiated on alfacalcidol $1 \mathrm{mcg}$ three times per week, the final doses within the oral and IV groups were not reported by the authors. Some studies propose that pulse alfacalcidol oral therapy is as effective as daily oral administration in regards to PTH suppressive effect $[11,15]$.

Some studies suggest that intermittent administration is associated with a lower incidence of hypercalcemia and may suppress PTH with more efficacy than daily administration of activated vitamin D [23,24]. One study showed that IV intermittent calcitriol therapy is the best route of administration in regards to PTH suppressive effect [6]. Another study also suggested that IV calcitriol administration in the early stage of kidney failure can prevent the exacerbation of parathyroid hyperplasia and delay the apparition of nodular hyperplasia [4]. Others demonstrated that IV calcitriol treatment has a superior effect on bone remodelling $[7,8]$. However, more recent publications have shown that high-dose intermittent oral administration may be as effective as IV administration in treating SHPT [1,9-11]. Zhou et al. published in 2009 a meta-analysis of randomized controlled trials comparing intermittent IV and oral calcitriol in chronic HD patients [12]. Six studies were considered for their metaanalysis and they showed that there were no significant differences between the two routes of administration in regards to efficacy and adverse effects (hypercalcemia and/ or hyperphosphatemia).

The response to activated vitamin D therapy may also be related to SHPT severity instead of the route of administration of calcitriol [9,25-27]. Obviously, activated vitamin D efficacy is also linked to patient's compliance with the drug regimen [28]. Nonetheless, the optimal route of administration of activated vitamin D is still debated [13] because there are limited randomized placebo-controlled studies that directly compare pulse-oral to pulse-IV activated vitamin $\mathrm{D}$ administration for the treatment of SHPT in ESRD.

Although it has not been demonstrated, we could postulate that oral alfacalcidol higher efficacy is partially related to the "first hepatic pass effect". For example, we can compare this phenomenon to Amiodarone class III antiarrhythmic action which is mostly related to the pharmacologic action of the hepatic metabolite $[29,30]$. Similarly, Alfacalcidol is a pro-drug that must undergo hepatic 25-hydroxylation before being active [5]. This hydroxylation may be greater when alfacalcidol is administered orally avoiding rapid peripheral catabolism. This phenomenon could lead to higher levels of 1.25 $(\mathrm{OH})_{2} \mathrm{D}_{3}$, higher intestinal calcium absorption, slightly higher levels of serum calcium and better control of SHPT. However, efficacy could be different for a vitamin $\mathrm{D}$ analog that would not be a pro-drug with hepatic metabolism. For sure, we cannot exclude some tubing adsorption with IV administration. Another potential explanation comes from the fact that IV administration of alfacalcidol yields a peak serum of medication that is faster and higher than the oral administration of alfacalcidol. Thus, it is possible that this phenomenon increases the catabolism of alfacalcidol and $1.25(\mathrm{OH})_{2} \mathrm{D}_{3}$.

Our secondary objective was to study the costeffectiveness of oral compared to IV alfacalcidol administration in HD. Oral administration is significantly cheaper, which is consistent with literature [31]. It is well known that SHPT in CKD patients has a significant economic burden and must soon be recognized and treated [31]. Savings are mainly related to lower drug price and reduced nursing time, which is a major issue in a context of nursing shortage.

Since our study is not a randomized control trial, we cannot exclude that the observed results are due to unmeasured or unknown factors, other than the route of alfacalcidol administration.

\section{Conclusions}

Although some studies have suggested that intermittent IV administration of activated vitamin $\mathrm{D}$ analogs may be associated with a better control of SHPT, it is not the case for alfacalcidol, a pro-drug that needs hepatic hydroxylation before being active. Moreover, our findings suggest that intermittent oral administration is even more effective than equivalent IV dosage in regards to PTH suppressive effect. For maintaining serum PTH levels within target limits or for compliance purposes, intermittent oral administration of alfacalcidol in an HD unit is a much more cost-effective strategy. In our unit, for 88 patients for whom intermittent activated 
vitamin D administration was considered medically appropriate, such a strategy represents an annual saving of 197678 \$CAN and significantly reduces nursing time required for drug administration during HD sessions.

\section{Competing interests}

The authors declare that they have no competing interests.

\section{Authors' contribution}

$\mathrm{MV}, \mathrm{ML}$ and $\mathrm{RB}$ conceived of the study and participated in its design and coordination and helped to draft the manuscript. JPL participated in the design of the study and performed the statistical analysis. DO, ML, ACNF and VP participated in the design of the study and coordination and helped to draft the manuscript. All authors read and approved the final manuscript.

\section{Acknowledgements}

We acknowledge Mme Naoual Elftouh, MSc, for her contribution in statistical analysis and Mme Martine Pettigrew for her contribution in Pharmaco-economic analysis.

Received: 24 April 2013 Accepted: 2 February 2014

Published: 4 February 2014

\section{References}

1. Levine BS, Song M: Pharmacokinetics and efficacy of pulse oral versus intravenous calcitriol in hemodialysis patients. J Am Soc Nephrol 1996, 7(3):488-496.

2. Kandula P, Dobre M, Schold JD, et al: Vitamin D supplementation in chronic kidney disease: a systematic review and meta-analysis of observational studies and randomized controlled trials. Clin J Am Soc Nephrol 2011, 6:50-62.

3. Costa AF, dos Reis LM, Ribeiro MC, Moysés RM, Jorgetti V: Effects of calcitriol on parathyroid function and on bone remodelling in secondary hyperparathyroidism. Nephrol Dial Transplant 2003, 18(4):743-749.

4. Taniguchi M, Tokumoto M, Tsuruya K, Hirakata H, lida M: Intravenous calcitriol therapy in an early stage prevents parathyroid gland growth. Nephrol Dial Transplant 2008, 23(11):3662-3669.

5. Kumar R: New clinical trials with vitamin $\mathrm{D}$ and analogs in renal disease. Kidney Int 2011, 80(8):793-796.

6. Liou HH, Chiang SS, Huang TP, Shieh SD, Akmal M: Comparative effect of oral or intravenous calcitriol on secondary hyperparathyroidism in chronic hemodialysis patients. Miner Electrolyte Metab 1994, 20(3):97-102.

7. Turk S, Akbulut M, Yildiz A, et al: Comparative effect of oral pulse and intravenous calcitriol treatment in hemodialysis patients: The effect on serum IL-1 and IL-6 levels and bone mineral density. Nephron 2002, 90(2):188-194.

8. Borazan A, Ustun H, Cefle A, Sekitmez N, Yilmaz A: Comparative efficacy of oral and intravenous calcitriol treatment in haemodialysis patients: Effects on serum biochemistry and cytokine levels. J Int Med Res 2003, 31(6):489-496.

9. Bacchini G, Fabrizi F, Pontoriero G, Marcelli D, di Filippo S, Locatelli F: "Pulse oral" versus intravenous calcitriol therapy in chronic hemodialysis patients: a prospective and randomized study. Nephron 1997, 77(3):267-272.

10. Palmer SC, McGregor DO, Macaskill P, Craig JC, Elder GJ, Strippoli GF: Meta-analysis: vitamin $\mathrm{D}$ compounds in chronic kidney disease. Ann Intern Med 2007, 147(12):840-853.

11. Tarrass F, Yazidi A, Sif H, Zamd M, Benghanem MG, Ramdani B: A randomized trial of intermittent versus continuous oral alfacalcidol treatment of hyperparathyroidism in end-stage renal disease. Clin Nephrol 2006, 65(6):415-418.

12. Zhou $\mathrm{H}, \mathrm{Xu} \mathrm{C}$ : Comparison of intermittent intravenous and oral calcitriol in the treatment of secondary hyperparathyroidism in chronic hemodialysis patients: a meta-analysis of randomized controlled trials. Clin Nephrol 2009, 71(3):276-285.

13. Mazess $R B$, Elangovan $L:$ A review of intravenous versus oral vitamin $D$ hormone therapy in hemodialysis patients. Clin Nephrol 2003, 59(5):319-325.

14. Mitwalli AH, Alam AA: Intermittent oral versus intravenous alfacalcidol in dialysis patients. Saudi J Kidney Dis Transpl 2000, 11(2):174-180.
15. Gu Y, Ding F, Chen N, et al: Comparisons between oral pulse alfacalcidol therapy and daily therapy in maintenance hemodialysis patients with secondary hyperparathyroidism: a randomized, controlled, and multicenter study. Ren Fail 2005, 27(2):205-212.

16. Kidney Disease: Improving Global Outcome (KDIGO) CKD-MBD Work Group: KDIGO clinical practice guideline for the diagnosis, evaluation, prevention, and treatment of Chronic Kidney Disease-Mineral and Bone Disorder (CKD-MBD). Kidney Int 2009, 113:S1-S130.

17. Pettigrew M, Soltys GIM, Bell RZ, et al: Tinzaparin reduces health care resource use for anticoagulation in hemodialysis. Hemodial Int 2011, 15(2):273-279.

18. Pena YT, Soyibo AK, Mc Growder D, Clarke TR, Barton EN: The importance of bone biomarkers in the diagnosis of renal osteodystrophy. West Indian Med J 2010, 59(3):332-337.

19. Kiattisunthorn K, Wutyam K, Indranoi A, Vasuvattakul S: Randomized trial comparing pulse calcitriol and alfacalcidol for the treatment of secondary hyperparathyroidism in haemodialysis patients. Nephrology 2011, 16(3):277-284

20. Moe S, Wazny LD, Martin JE: Oral calcitriol versus oral alfacalcidol for the treatment of secondary hyperparathyroidism in patients receiving hemodialysis: a randomized, crossover trial. Can J Clin Pharmacol 2008, 15(1):e36-e43.

21. Al-Hilali N, Al-Humoud H, Al-Helal B, Al-Azmi M, Al-Kandari NH, Johny KV: Intravenous alfacalcidol once weekly suppresses parathyroid hormone in hemodialysis patients. Ther Apher Dial 2008, 12(2):137-142.

22. El-Shafey EM, Alsahow AE, El-Nagar GF, Ezzat A: Intravenous alfacalcidol once weekly pulse therapy for secondary hyperparathyroidism in hemodialysis patients. Ren Fail 2011, 33(3):329-333.

23. Coburn JW: Use of oral and parenteral calcitriol in the treatment of renal osteodystrophy. Kidney Int 1990, 38(Suppl 29):S54-S61.

24. Tsukamoto Y, Nomura M, Takahashi Y, et al: The "oral 1,25 dihydroxyvitamin D3 pulse therapy" in hemodialysis patients with severe secondary hyperparathyroidism. Nephron 1991, 57(1):23-28.

25. Quarles LD, Yohay DA, Carroll BA, et al: Prospective trial of pulse oral versus intravenous calcitriol treatment of hyperparathyroidism in ESRD. Kidney Int 1994, 45(6):1710-1721.

26. Quarles LD, Indridason OS: Calcitriol administration in end-stage renal disease: intravenous or oral? Pediatr Nephrol 1996, 10(3):331-336.

27. Indridason OS, Quarles LD: Oral versus intravenous calcitriol: is the route of administration really important? Curr Opin Nephrol Hypertens 1995, 4(4):307-312.

28. Andress $\mathrm{DL}$ : Intravenous versus oral vitamin $\mathrm{D}$ therapy in dialysis patients: what is the question? Am J Kidney Dis 2001, 38(5 Suppl 5):S41-S44.

29. Talajic M, DeRoode MR, Nattel S: Comparative electrophysiologic effects of intravenous amiodarone and desethylamiodarone in dogs: evidence for clinically relevant activity of the metabolite. Circulation 1987, 75:265-271.

30. Chow MS: Intravenous amiodarone: pharmacology, pharmacokinetics, and clinical use. Ann Pharmacother 1996, 30(6):637-643.

31. Joy MS, Karagiannis PC, Peyerl FW: Outcomes of secondary hyperparathyroidism in chronic kidney disease and the direct costs of treatment. J Manag Care Pharm 2007, 13(5):397-411.

doi:10.1186/1471-2369-15-27

Cite this article as: Lessard et al:: Comparison of oral and intravenous

Alfacalcidol in chronic hemodialysis patients. BMC Nephrology 2014 15:27.

\section{Submit your next manuscript to BioMed Central and take full advantage of:}

- Convenient online submission

- Thorough peer review

- No space constraints or color figure charges

- Immediate publication on acceptance

- Inclusion in PubMed, CAS, Scopus and Google Scholar

- Research which is freely available for redistribution 